\title{
Texture, Microstructure and Mechanical Properties of 6111 Aluminum Alloy Subject to Rolling Deformation
}

\author{
Lixin Zhang ${ }^{a}$, Yihan Wang ${ }^{a}$, Xiaohui Yang ${ }^{a}$, Kai $\mathrm{Li}^{a}$, Song $\mathrm{Ni}^{a}{ }^{*}$, Yong Du ${ }^{a}$, Min Song ${ }^{a}$ \\ ${ }^{a}$ State Key Laboratory of Powder Metallurgy, Central South University, Changsha, 410083, China
}

Received: June 04, 2017; Accepted: July 03, 2017

\begin{abstract}
The mechanical properties, texture and microstructural evolution of a 6111 aluminum alloy during hot rolling and cold rolling deformation were systematically investigated in this article. The results show that cold rolling and hot rolling have significant effects on the tensile behaviors of the alloy. The shear texture and recrystallization texture mainly formed during the hot rolling deformation process, while the rolling texture mainly formed during the cold rolling deformation. The grain refinement mechanisms depend significantly on the rolling process. Movement of shear zone and recrystallization are the main grain refinement mechanisms during the hot rolling process, while dislocations tangling is the main grain refinement mechanism during the cold rolling process. The recrystallization textures and shear textures affect the anisotropy in elongation but the rolling textures affect significantly the anisotropy in yield strength.
\end{abstract}

Keywords: Al-Mg-Si alloy, texture, rolling, mechanical properties

\section{Introduction}

Aluminum alloys have been widely used in aviation, medical and automobile industries due to their high strength to weight ratio, excellent corrosion and fatigue resistances, and good forming properties ${ }^{1-5}$. Since $6 \mathrm{xxx}$ aluminum alloys (Al-Mg-Si-Cu series) show good bake hardening temper, 6xxx aluminum alloys are well suitable for automotive skin and other structure members in machinery ${ }^{6}$. The fabrication process of a typical $6 \mathrm{xxx}$ alloy mainly consists of casting, scalping, homogenization, hot rolling, intermediate annealing, cold rolling, solution treatment, pre-aging, natural aging, forming, painting and paint baking ${ }^{2,7}$. During the rolling process, an ingot sheet will be deformed to the final shape and size, accompanied by the generation of textures. Normally, plastic deformation, such as rolling, extrusion and drawing, will form a strong texture, particularly at room temperature ${ }^{8-12}$. For face centered cubic (f.c.c.) structured metals and alloys, the textures formed during rolling can be usually divided into three main types: recrystallization texture, shear texture and rolling texture. One of the most accurate methods to measure the texture is orientation density function (ODF), which could be obtained by the pole figure calculation of several different crystal surfaces. The different textures correspond to specific Euler angles $\left(\varphi_{1}, \varphi, \varphi_{2}\right)$ in ODF. Table 1 shows the main textures and their corresponding Euler angles and Miller indices ${ }^{7,12-15}$.

Different processing parameters can generate various textures of the alloys, with different mechanical properties and microstructures. For example, Wang et al. ${ }^{7}$ reported that

* e-mail: song.ni@csu.edu.cn different heating rates during solution treatment resulted in the formation of different textures, and thus affected the mechanical properties and microstructures of $\mathrm{Al}-0.8 \mathrm{Mg}$ $0.9 \mathrm{Si}-0.5 \mathrm{Cu}-0.2 \mathrm{Fe}-0.1 \mathrm{Mn}$ alloy. The alloy after solution treatment with fast heating rate shows a strong anisotropy and Cube texture, thus weakens the mechanical properties. While the alloy after solution treatment with slow heating rate shows much weaker anisotropy and a combined texture of Cube, P, R, Goss and Brass components, with improved mechanical properties. The grains of the fast heated alloy are almost equiaxed grains, while the slowly heated alloy comprises of elongated grains.

The textures of the materials can have a great influence on the mechanical performance. For example, Zhao et al. ${ }^{16}$ reported that the Goss-grains present a significant crack deflection effect in the toughness testing, while Brass-grains, S-grains and Copper-grains have little influence on the crack propagation in the toughness testing. Goss/Brass volume fraction ratio has great influence on the fracture toughness of the alloy, and the higher the ratio, the higher the fracture toughness of the materials ${ }^{16}$.

Most previous studies about the effect of texture evolution on the mechanical properties of aluminum alloys are concentrated on just one single pass of the rolling, either hot rolling or cold rolling ${ }^{11,17-21}$. It should be noted that multipass rolling deformation, including both cold rolling and hot rolling, are required for 6111 aluminum alloys to be used as automotive skin and other structural members in machinery, and the texture evolution during each rolling pass might affect significantly the final mechanical properties. So it is necessary to investigate the texture evolution and its effect on 
Table 1. Miller indices and Euler angles of f.c.c. rolling and shear orientations.

\begin{tabular}{|c|c|c|c|c|c|}
\hline \multirow{2}{*}{ Notation } & \multirow{2}{*}{$\begin{array}{l}\text { Miller indices } \\
\{\mathrm{h} \mathrm{k} 1\}<\mathrm{u} \mathrm{v} \mathrm{w}>\end{array}$} & \multicolumn{3}{|c|}{ Euler angles $\left({ }^{\circ}\right)$} & \multirow{2}{*}{ Texture type } \\
\hline & & $\varphi_{1}$ & $\varphi$ & $\varphi_{2}$ & \\
\hline Cube & $\{001\}<100>$ & 0 & 0 & 0 & \multirow{3}{*}{ Recrystallization } \\
\hline $\mathrm{P}$ & $\{011\}<122>$ & 70 & 45 & $0 / 90$ & \\
\hline $\mathrm{R}$ & $\{124\}<211>$ & 59 & 37 & 63 & \\
\hline Brass & $\{011\}<211>$ & 35 & 45 & 0 & \multirow{5}{*}{ Rolling } \\
\hline Copper & $\{112\}<111>$ & 90 & 35 & 45 & \\
\hline Goss & $\{011\}<100>$ & 0 & 45 & 0 & \\
\hline $\mathrm{S}$ & $\{123\}<634>$ & 59 & 37 & 63 & \\
\hline $\mathrm{D}$ & $\{4411\}<11118>$ & 90 & 27 & 45 & \\
\hline Rotate cube & $\{001\}<110>$ & 45 & 0 & 0 & \multirow{4}{*}{ Shear } \\
\hline Inverse brass & $\{112\}<110>$ & 0 & 35 & 45 & \\
\hline $\mathrm{E}$ & $\{111\}<110>$ & $0 / 60$ & 55 & 45 & \\
\hline $\mathrm{F}$ & $\{111\}<112>$ & $30 / 90$ & 55 & 45 & \\
\hline
\end{tabular}

the mechanical properties after each pass during the whole rolling process. In this paper, a 6111 aluminum alloy was fabricated by ingot metallurgy, followed by hot rolling and cold rolling processes. The texture evolution and its effect on the mechanical properties were systematically investigated.

\section{Experimental}

The alloy was fabricated by a medium frequency induction furnace, using $99.9 \%$ pure aluminum, $99.9 \%$ pure magnesium, 99.9\% pure iron, $99.9 \%$ pure nickel and master alloys of Al-50 wt.\%Cu, Al-20 wt.\%Si and Al-9 wt.\% Mn. The ingot was casted in graphite crucible and then cooled down in water cooled copper mould, and the dimension of the ingot is $100 \mathrm{~mm} \times 100 \mathrm{~mm} \times 60 \mathrm{~mm}$. The chemical composition of ingot is determined by optical direct-reading spectrometer ARL-4460 after mechanical grinding and polishing. Table 2 shows the chemical composition of the fabricated alloy.

The surface oxide of the ingot was taken off by mechanical lapping and followed by homogenization heat treatment under a vacuum condition for 20 hours at $555^{\circ} \mathrm{C}$. After homogenization treatment, the ingot was cut into 5 sheets with a dimension of $100 \mathrm{~mm} \times 100 \mathrm{~mm} \times 10 \mathrm{~mm}$ (length $\times$ width $\times$ height). The length, width and height of the sheets were used as the rolling direction (RD), the transverse direction (TD) and the normal direction (ND) during the subsequent rolling process, respectively. All the rolling passes were undertaken at a speed of $0.2 \mathrm{~m} \mathrm{~s}^{-1}$ under nominally dry condition. The sheets was pre-heated in a muffle furnace at $450^{\circ} \mathrm{C}$ for 1 hour before rolling and followed by hot rolling process. Then the sheets were hot rolled to $7 \mathrm{~mm}$ with the rolling reduction of $30 \%$ (HR30) after the first rolling pass.
During the second rolling pass the sheets were hot rolled to $5 \mathrm{~mm}$ with the accumulated rolling reduction of $50 \%$ (HR50). After two passes of hot rolling deformation, the sheets were natural cooled down to the room temperature. The cold rolling process was at room temperature with $1 \mathrm{~mm}$ reduction for each pass. After 2 passes of the cold rolling deformation, the height of the sheets was $3 \mathrm{~mm}$ with the accumulated rolling reduction being $70 \%(\mathrm{HR}+\mathrm{CR} 70)$. Finally, the sheets were rolled into $1 \mathrm{~mm}$ thick sheet, with the total rolling reduction of $90 \%(\mathrm{HR}+\mathrm{CR} 90)$.

The microstructures and crystallographic texture of all the samples were tested on the RD-TD sections. Bulk texture measurements were obtained from three incomplete pole figures $\{220\},\{200\},\{111\}$ using a PANNalytical X'PertPRO MRD goniometer with a $\mathrm{Cu}$ tube operating at $40 \mathrm{kV}$. Before texture measurements the samples were machined and carefully mechanically polished to obtain mirror-like surfaces. All the texture measurements were performed on $10 \times 8(\mathrm{RD} \times \mathrm{TD}) \mathrm{mm}^{2}$ surfaces of the rolling samples. The microstructures of the samples were examined by electron backscattering diffraction (EBSD) in a FEI Quanta FEG 250 field emission scanning electron microscope (SEM). The samples for EBSD observations were electrolytic polished in a solution of $30 \mathrm{vol} . \% \mathrm{HNO}_{3}$ methanol under a temperature of $-30^{\circ} \mathrm{C}$ and an applied voltage of $14 \mathrm{~V}$. Dogbone-shaped samples for mechanical properties testing with $8 \mathrm{~mm}$ gauge length were machined and mechanically polished. The mechanical properties of the different rolling deformed samples were investigated at room temperature along the three directions of $0^{\circ}, 45^{\circ}$ and $90^{\circ}$ with respect to the rolling direction. Deformation information and notation of the samples were shown in Table 3. Mechanical properties

Table 2. Composition of the tested alloy (mass fraction, \%).

\begin{tabular}{cccccccc}
\hline Element & $\mathrm{Al}$ & $\mathrm{Mg}$ & $\mathrm{Si}$ & $\mathrm{Cu}$ & $\mathrm{Mn}$ & $\mathrm{Fe}$ & $\mathrm{Ni}$ \\
\hline AA-6111 & balance & 1.08 & 0.89 & 0.37 & 0.21 & 0.12 & 0.23 \\
\hline
\end{tabular}


Table 3. Deformation information and number of the samples.

\begin{tabular}{cccc}
\hline Deformation & Rolling process & $\begin{array}{c}\text { Directions respect to the } \\
\text { rolling direction }\end{array}$ & Notation \\
\hline $0 \%$ & - & - & HR30-0 \\
& Hot rolling & $0^{\circ}$ & HR30-45 \\
& & $45^{\circ}$ & HR30-90 \\
\hline & & $90^{\circ}$ & HR50-0 \\
& Hot rolling & $0^{\circ}$ & HR50-45 \\
& & $45^{\circ}$ & HR50-90 \\
\hline & & $90^{\circ}$ & HR+CR70-0 \\
& Cold rolling & $0^{\circ}$ & HR+CR70-45 \\
& & $45^{\circ}$ & HR+CR70-90 \\
\hline
\end{tabular}

were performed using an Instron-3369 universal testing machine with a strain rate of $1.5 \times 10^{-5} \mathrm{~s}^{-1}$.

\section{Results}

\subsection{Mechanical properties}

Figure 1 shows the engineering stress-engineering strain curves of the HR30, HR50, HR+CR70 and HR+CR90 specimens along three directions of $0^{\circ}, 45^{\circ}, 90^{\circ}$ with respect to the rolling direction, respectively. In order to clearly see the changes of anisotropy in mechanical properties during hot rolling and cold rolling deformation, the yield strength and $\Delta \sigma$ (The difference between the maximum yield stress and the minimum yield stress) of samples were listed in table 4. It can be seen from Figure 1a that the mechanical properties of the HR30 specimens along three different directions are almost the same, with the yield strength being about 100 $\mathrm{MPa}$. With increasing the hot rolling deformation to $50 \%$, the mechanical properties (particularly the elongation) of the HR50 specimens start to show difference along three directions, as shown in Figure 1b. The HR50-90 specimen has the highest yield strength but the lowest elongation, and the HR50-0 specimen shows the highest elongation but the lowest yield strength. The variation of anisotropy of the yield strength is very small, but the anisotropy of elongation shows significant difference during hot rolling deformation. After cold rolling deformation the yield strength of $\mathrm{HR}+\mathrm{CR} 70$ along three directions shows significant difference, as shown in Figure $1 \mathrm{c}$, and the $\Delta \sigma$ is $10.79 \mathrm{MPa}$ as shown in table 4 . The mechanical properties of $\mathrm{HR}+\mathrm{CR} 90$ along three directions are shown in Figure 1d. With the rolling deformation increasing to $90 \%$, the difference between the maximum yield strength and the minimum yield strength become larger with the $\Delta \sigma$ being $22.30 \mathrm{MPa}$ as shown in table 4 , and the anisotropy of elongation along three directions shows similar trend to that of HR+CR70. The HR+CR90-90 sample has the highest yield strength of about 272.63 MPa, while the HR+CR90-0 sample has the best elongation of about $10.04 \%$. Obviously, the cold rolling deformation has significant influence on the mechanical properties of the alloy, especially for the anisotropy of the yield strength.

The mechanical properties of the specimens after different rolling deformation along three directions were shown in Figure 2. It can be seen that evolution trend of the mechanical properties along three directions shows similar feature, with the strength increasing and elongation is decreasing with the rolling reduction. During the hot rolling deformation the yield strength of the alloy increase slightly with the increasing of the hot rolling deformation but plastic loss is not much. But during cold rolling the yield of the alloy have a marked increase and plastic also decrease significantly. During tensile deformation, the hot rolled specimens show typical work hardening after yielding, while the cold rolled specimens shows typical softening after yielding. This different is mainly due to the recovery during tensile deformation after cold rolling deformation.

\subsection{Texture evolution}

Bulk texture evolution of the alloy was measured using $\mathrm{X}$-ray diffraction. The main texture types for f.c.c. structured materials are shown in Table 1 and Figure 3 a shows a schematic of the ideal positions of the prominent orientations for $\varphi_{2}=0^{\circ}$, $45^{\circ}, 65^{\circ}$ ODFs sections, respectively. The symbols with various colors in the figure indicate the location of standard texture components in the 2D ODF. The main recrystallization texture shown here is Cube $\{011\}<211>$. The main rolling texture components consist of Brass $\{011\}<111>$, Copper $\{112\}<111>$, Goss $\{011\}<100>$, S $\{123\}<634>$ and D $\{44$ 

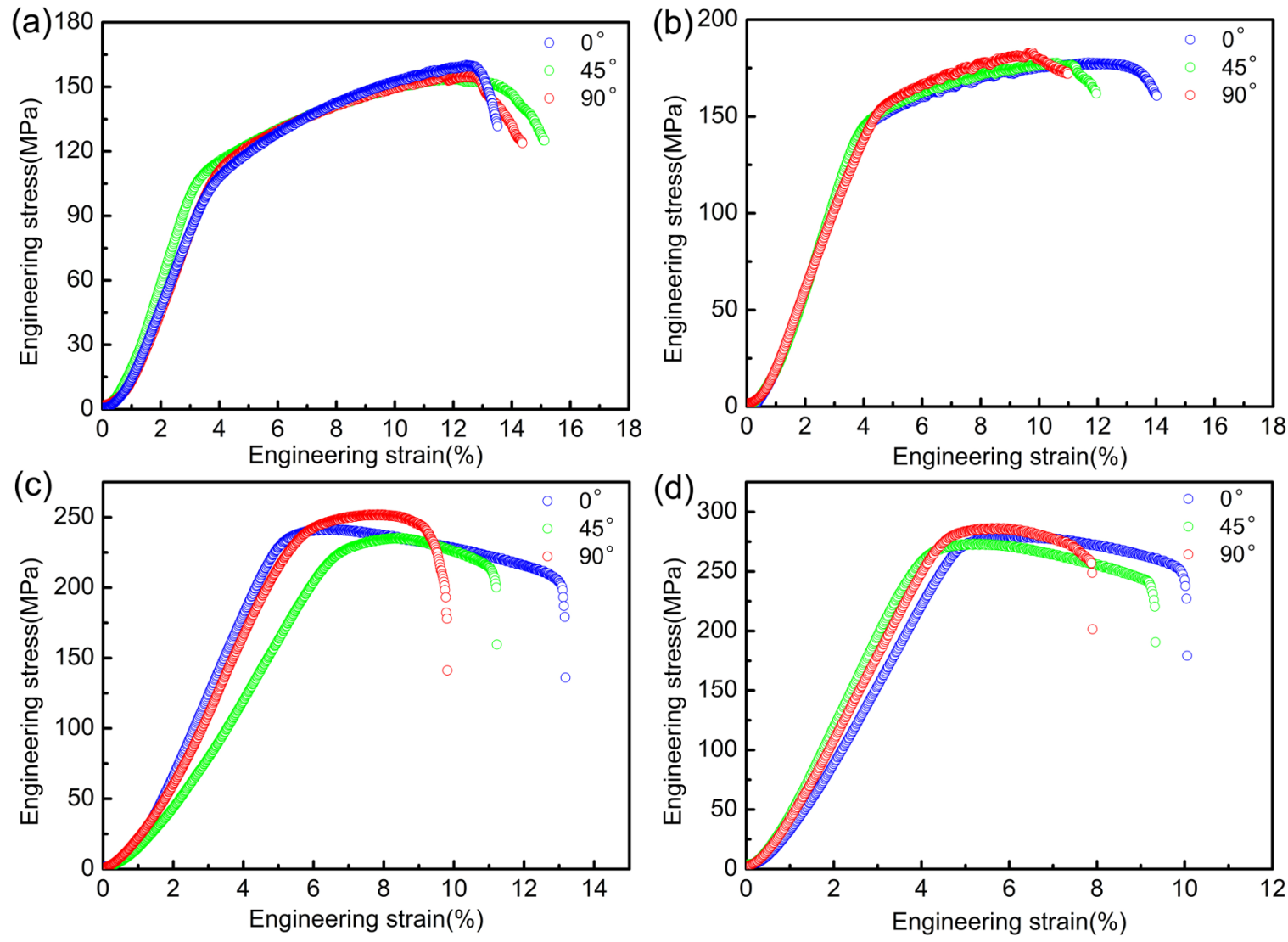

Figure 1. Engineering stress-engineering strain curves of the samples (a) HR30, (b) HR50, (c) HR+CR70, (d) HR+CR90 along three directions of $0^{\circ}, 45^{\circ}$ and $90^{\circ}$ with respect to the rolling direction.

$11\}<11118>$. The main shear texture components consist of Rotate cube $\{001\}<110>$, Inverse brass $\{112\}<110>$, E $\{111\}<110>$ and $F\{111\}<112>$ (Table 1). Figure $3 b-f$ shows the $\varphi_{2}=0^{\circ}, 45^{\circ}, 65^{\circ}$ ODFs sections of the samples 0, HR30, HR50, HR+CR70 and HR+CR90, respectively. The ODFs with different rolling deformation have different values corresponding to different angles of $\varphi$ and $\varphi_{1}$, with the $\varphi_{2}$ being fixed as $0^{\circ}, 45^{\circ}, 65^{\circ}$. The crystal orientation of sample 0 is random after homogenizing treatment, so the ODFs of sample 0 as shown in Figure $3 b$ show no obvious texture. With increasing the hot rolling deformation degree, the orientation of sample HR30 is not random and starts to

Table 4. Statistics of mechanical properties of samples.

\begin{tabular}{cccc}
\hline Deformation & Samples & Yield strength(Mpa $)$ & $\begin{array}{c}\Delta \sigma(\mathrm{MPa}) \\
\left(\sigma_{\max }-\sigma_{\min }\right)\end{array}$ \\
\hline \multirow{2}{*}{$30 \%$} & HR30-0 & 101.47 & 4.05 \\
& HR30-45 & 100.37 & 104.42 \\
\hline \multirow{2}{*}{$50 \%$} & HR30-90 & 140.65 & 8.86 \\
& HR50-0 & 140.49 & 10.79 \\
\hline \multirow{2}{*}{$70 \%$} & HR50-45 & 149.35 & \\
\hline & HR+CR70-0 & 222.36 & 22.30 \\
\hline
\end{tabular}



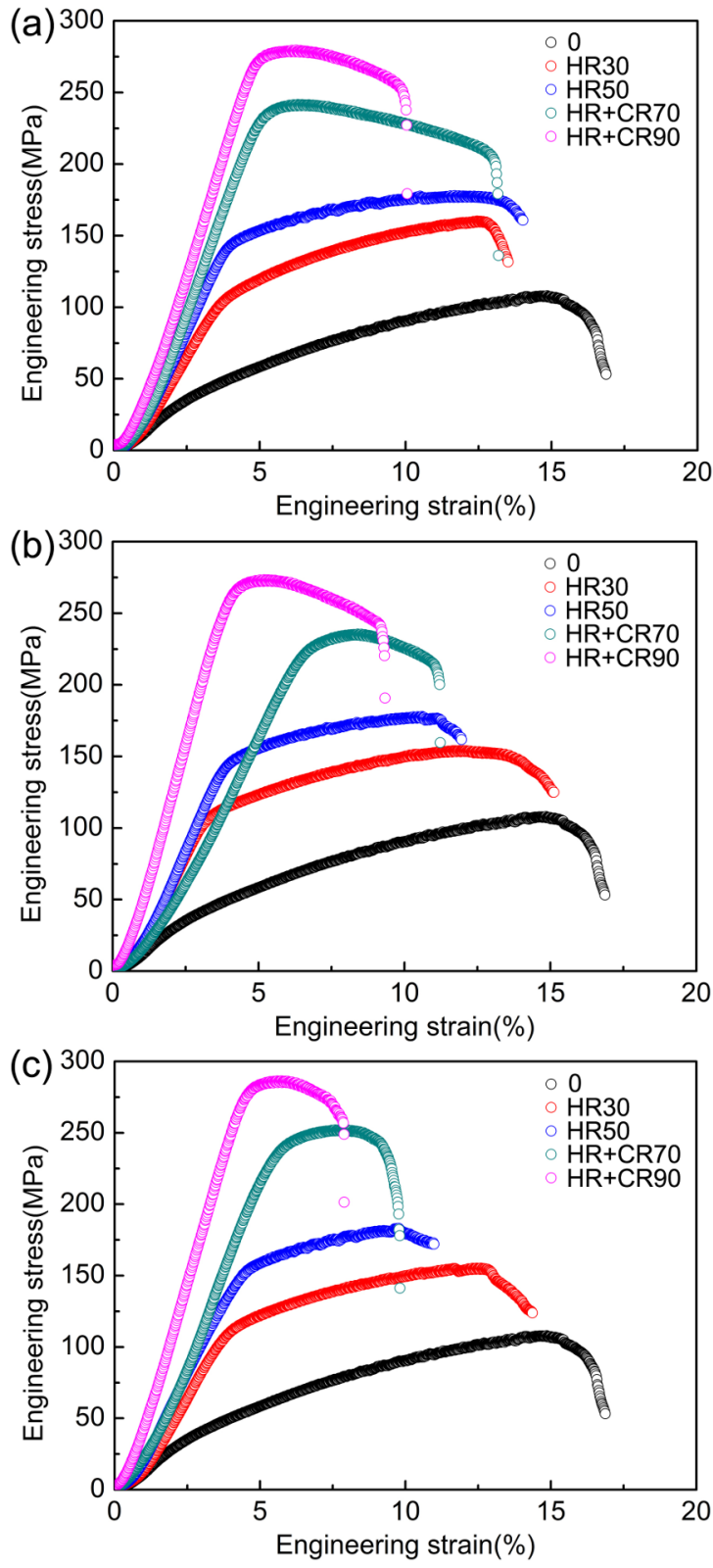

Figure 2. Engineering stress-engineering strain curves along three directions of (a) $0^{\circ}$, (b) $45^{\circ}$, (c) $90^{\circ}$ with different rolling deformation.

show some textures in the ODFs, as shown in Figure 3c. The texture shown here are mainly shear texture and the intensity of the shear texture is not very strong, except for texture $\mathrm{E}\{111\}<110>$. The ODFs of the sample HR50 is shown in Figure 3d. With increasing the hot rolling degree, the intensity of the shear texture and recrystallization texture get stronger. After the first cold rolling process, the intensity of the texture in ODFs of HR+CR70 sample has obvious variation, as shown in Figure 3e. All the intensity of shear textures becomes weaker, but all the intensity of rolling texture becomes stronger. With increasing the cold rolling deformation degree, the intensity of rolling textures become (a)

(b)

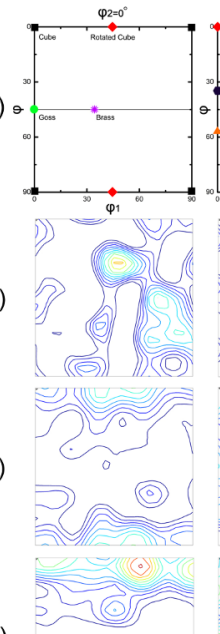

(d)
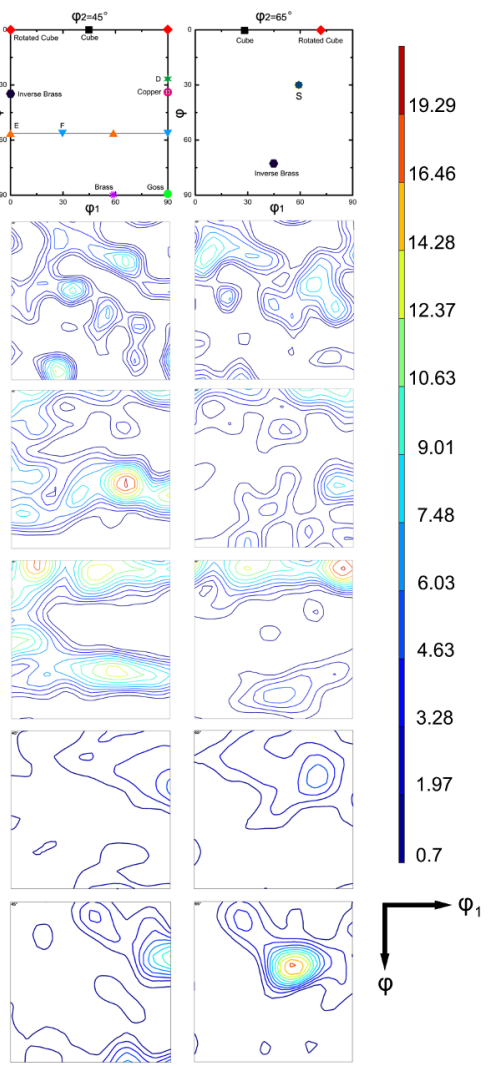

Figure 3. (a) standard ODFs and ODFs of the samples (b) 0, (c) HR30, (d) HR50, (e) HR+CR70 and (f) HR+CR90.

stronger and the texture $\mathrm{S}\{123\}<634>$ is the strongest, as shown in Figure $3 \mathrm{f}$.

The volume fraction of different texture components are calculated from bulk texture analysis of the specimens. Trends of all the textures are shown in Figure 4a. The sample after homogenization treatment shows random orientation, without obvious texture. The evolution of the texture obviously divided into two groups. The groups of the shear textures and the recrystallization textures represented by dotted line and black line are dominant during the hot rolling deformation. During the cold rolling deformation, the group of the rolling textures represented by thin lines becomes stronger, and the shear textures and recrystallization textures become weaker.

Figures $4 \mathrm{~b}-4 \mathrm{~d}$ shows the evolutions of the recrystallization texture, shear texture and rolling texture, respectively. Figure $4 \mathrm{~b}$ shows the evolution of Cube texture. The volume fraction of Cube texture increases with increasing the hot rolling deformation degree. During the cold rolling deformation, the volume fraction of Cube texture decreases rapidly. Figure $4 \mathrm{c}$ shows the evolution of the shear textures. E texture and $\mathrm{F}$ texture are constantly strengthened with increasing the hot rolling deformation degree. Rotated cube texture and Inverse brass texture reach the maximum volume fractions for the sample HR30 and these textures become slightly weaker for HR50. Figure $4 \mathrm{~d}$ shows the evolution of the rolling texture. 

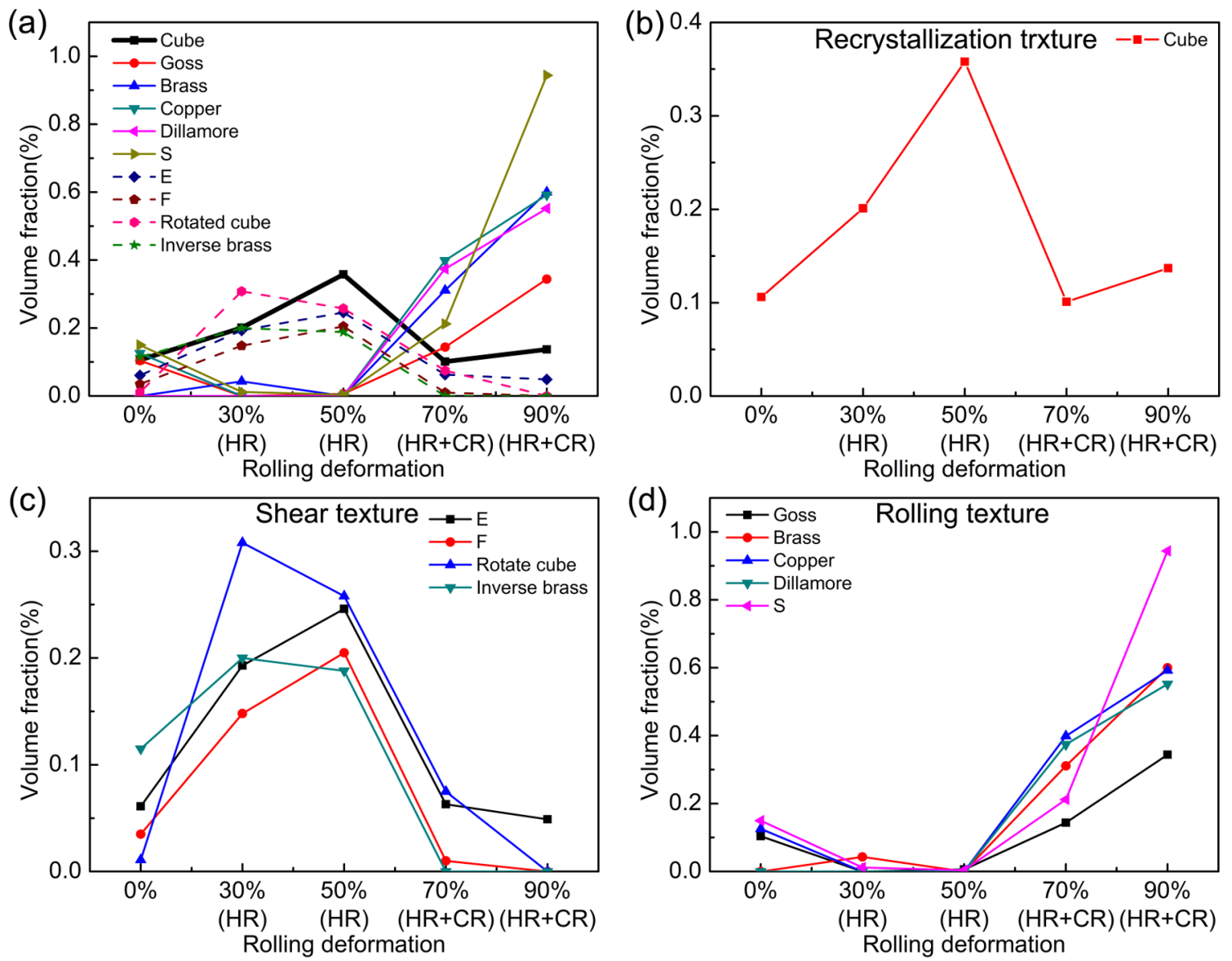

Figure 4. The variations in the volume fraction of (a) all the textures, (b) recrystallization texture, (c) shear texture and (d) rolling texture with increasing the rolling deformation.

Rolling texture is very weak during hot rolling deformation. Most of the grains come up to a certain orientation to form strong rolling texture because of the severe grain rotation during cold rolling process. All the rolling textures become stronger with increasing the cold rolling deformation, and $\mathrm{S}$ texture mainly formed at large cold rolling deformation stage.

\subsection{Microstructures}

Figure 5 shows the EBSD images of the samples 0 , HR30, HR50, HR+CR70 and HR+CR90. The grains of the sample 0 are almost equiaxed with random orientation and the grain size is of $\sim 350 \mu \mathrm{m}$, as shown in Figure 5a. After $30 \%$ hot rolling deformation the specimen starts to show small misorientation inside the grains, as shown in Figure 5b. The slight color transition inside the grains shown in Figure $5 \mathrm{~b}$ represents a tiny orientation difference within the grains. These misorientations are less than $15^{\circ}$ and not large enough to form a high angle grain boundary. Shearing deformation and recrystallization led to the formation of a lot of small grain bands inside the original grains (arrowed in Figure 5b). With increasing the hot rolling deformation degree the grains get further refinement, as shown in Figure 5c. Because of the interaction of shear zone, dislocations and recrystallization make some areas inside the grains break and refine, as shown in the circles in Figure 5c. After the first pass cold rolling deformation, the original grains are elongated along the rolling direction, as shown in Figure $5 \mathrm{~d}$. The original grains were seriously broken and refined to smaller equiaxed grains, and the orientation of the broken grains is not all uniform during the first pass cold rolling deformation. The broken small grains show similar orientation to the original grains. With increasing the rolling deformation to $90 \%$, the grains formed banded structure along the ND after cold rolling process, as shown in Figure 5e. The original grains disappear completely and the orientation of the refined grains is uniform.

Rolling process is not only to make the alloy sheet be deformed to the final shape but also to refine the grains. Grains are refined by the interaction of dislocations during deformation ${ }^{21}$. Usually the dislocation slip and the deformation of the alloy are uneven. To coordinate the deformation, geometrically necessary dislocations (GND) are generated and play an important role as a kind of coordination dislocations. 

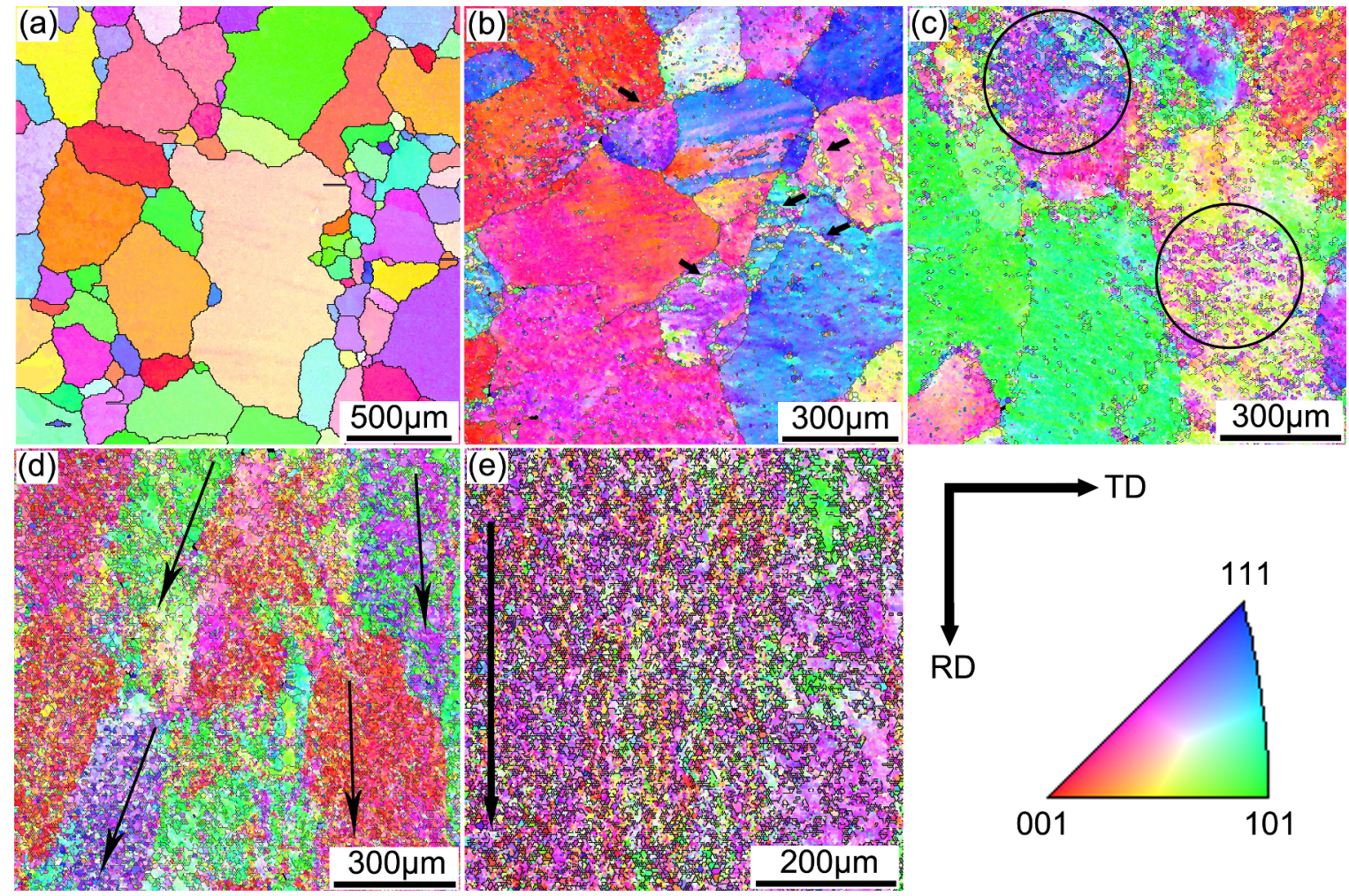

Figure 5. EBSD maps of the samples (a) 0, (b) HR30, (c) HR50, (d) HR+CR70 and (e) HR+CR90.

Many early works has explored the GND during deformation by $\mathrm{EBSD}^{22,23}$. The density of GND with different deformation samples from EBSD is shown in Figure 6. During hot rolling deformation the density of the GND has no obvious increase with the density mainly between $(0-10) \times 10^{12} \mathrm{~m}^{-2}$ and $(10-20) \times 10^{12} \mathrm{~m}^{-2}$, as shown in Figure $6 \mathrm{a}$ and $6 \mathrm{~b}$. The density of GND increases obviously mainly between (10$20) \times 10^{12} \mathrm{~m}^{-2}$ and $(20-30) \times 10^{12} \mathrm{~m}^{-2}$ of HR+CR70. With the increasing of the cold rolling deformation the density of GND keep increasing. For the HR+CR90, the density of GND is mainly between $(20-30) \times 10^{12} \mathrm{~m}^{-2}$ and $(30-40) \times 10^{12}$ $\mathrm{m}^{2}$. In the process of hot rolling, the increase of density of GND is not obvious, but in the process of cold rolling, the density of GND obviously increases with the increase of rolling deformation.

\section{Discussion}

The experimental results have revealed that the rolling deformation has significant influence on the texture evolution of 6111 aluminum alloy. During hot rolling deformation the recrystallization textures and shear textures dominate the microstructures, while the rolling texture dominates the microstructures during the cold rolling deformation. The dislocations formed by rolling deformation provide nucleation sites for the recrystallization. In addition, the hot rolling temperature $\left(>450^{\circ} \mathrm{C}\right)$ is higher than the recrystallization temperature $\left(350 \sim 420^{\circ} \mathrm{C}\right)$ of 6111 aluminum alloy. High temperature and deformation are contributed to the recrystallization of the alloy so the volume fraction of Cube texture constantly increases during the hot rolling process. However, the volume fraction of Inverse brass texture and Rotate cube texture do not keep increasing with increasing the hot rolling deformation degree. It could be inferred that the formation of shear texture will be affected by the rolling temperature and deformation degree during the hot rolling process. Rotate cube texture and Inverse brass texture are mainly formed at low hot rolling deformation degree, and $\mathrm{E}$ texture and $\mathrm{F}$ texture are enhanced with increasing the hot rolling deformation degree. During cold deformation, all the rolling textures become stronger with increase the cold rolling deformation degree, and $\mathrm{S}$ texture is mainly formed at large cold rolling deformation stage.

Defects nucleated during shear deformation could provide nucleation sites for recrystallization. The combination of shear deformation and recrystallization make grains refinement occurs at some regions inside the original grains. While cold rolling deformation makes the original grains completely break into many equiaxed grains. During cold rolling process, the temperature is not high enough for recrystallization so the recrystallization becomes much weaker. The grain refinement mainly depends on the slipping and piling up 

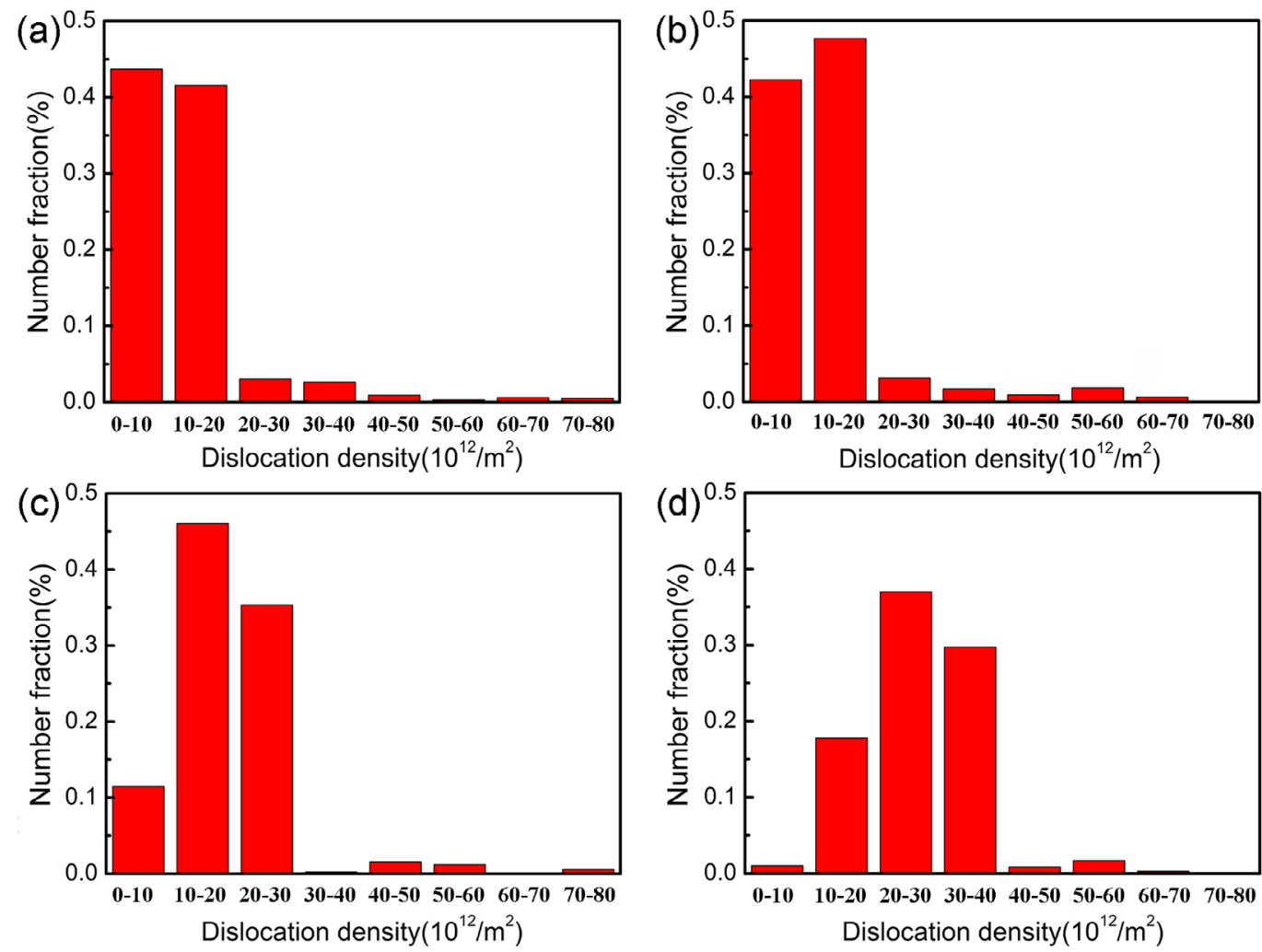

Figure 6. Geometrically necessary dislocation distribution of the samples (a) HR30, (b) HR50, (c) HR+CR70 and (d) HR+CR90.

of the dislocations. The rearrangement of the dislocations during deformation form many subgrains by generating small angle grain boundaries in the grains. And with increasing the deformation degree the small angle grain boundaries further transform into large angle grain boundaries. Then the banded structure was replaced by the small equiaxed grains. The influence of grains refinement during the cold rolling process is more obvious than that during the hot rolling process.

The density of geometrically necessary dislocations shown in Figure 6 proves that the pile-up of the dislocations is not severe during the hot rolling deformation since the density of the geometrically necessary dislocation changes little. During cold rolling deformation the increase of the density of the geometrically necessary dislocations with the cold rolling deformation degree proves that the pile-up of the dislocations become more and more seriously.

Shear textures and recrystallization textures are mainly formed during the hot rolling process, but rolling textures are mainly formed during the cold rolling process. The textures make the alloy have anisotropy in the mechanical properties. The results from the tensile tests show that the shear texture and recrystallization texture mainly influence the anisotropy of elongation along three directions of $0^{\circ}$, $45^{\circ}$ and $90^{\circ}$ with respect to the rolling direction, but have less influence on the anisotropy of the yield strength. On the contrary, the rolling texture mainly has influence on the anisotropy of the yield strength along three directions, but has less influence on the anisotropy of elongation.

\section{Conclusion}

This article conducted a detailed study of the mechanical properties, texture and microstructural evolution of a 6111 aluminum alloy subject to rolling deformation, with the following conclusions be drawn:

(1) During the hot rolling deformation, the main textures are shear texture and recrystallization texture. Different shear textures formed at different hot rolling deformation stage, with Rotate cube $\{001\}<110>$ and Inverse brass $\{112\}<110>$ mainly forming at low deformation stage and other shear textures increasing with the hot rolling deformation degree. On the other hand, rolling texture dominates the cold rolling deformation, with S texture mainly forming at large rolling deformation stage during cold rolling deformation.

(2) The grain refinement mainly depends on shear deformation and recrystallization during the hot rolling deformation process, and mainly depends on dislocations tangling during cold rolling deformation process.

(3) Different types of textures formed during the hot rolling and cold rolling processes have significant effects on the mechanical anisotropy of the alloy. The recrystallization 
texture and shear texture make the alloy show anisotropy in elongation, and the rolling texture make the alloy show anisotropy in the yield strength.

\section{Acknowledgement}

The financial support from National Natural Science Foundation of China (51501230) is appreciated.

\section{References}

1. Burger GB, Gupta AK, Jeffrey PW, Loyd DJ. Microstructural control of aluminum sheet used in automotive applications. Materials Characterization. 1995;35(1):23-39.

2. Engler O, Hirsch J. Texture control by thermomechanical processing of AA6xxx Al-Mg-Si sheet alloys for automotive applications - a review. Materials Science and Engineering: A. 2002;336(1-2):249-262.

3. Ghosh M, Miroux A, Kestens LAI. Correlating $r$-value and through thickness texture in Al-Mg-Si alloy sheets. Journal of Alloys and Compounds. 2015;619:585-591.

4. Miller WS, Zhuang L, Bottema J, Wittebrood AJ, De Smet P, Haszler A, et al. Recent development in aluminium alloys for the automotive industry. Materials Science and Engineering: A. 2000;280(1):37-49.

5. Hirsch J, Al-Samman T. Superior light metals by texture engineering: Optimized aluminum and magnesium alloys for automotive applications. Acta Materialia. 2013;61(3):818-843.

6. Engler O, Schäfer C, Myhr OR. Effect of natural ageing and pre-straining on strength and anisotropy in aluminium alloy AA 6016. Materials Science and Engineering: A . 2015;639:65-74.

7. Wang X, Guo M, Cao L, Luo J, Zhang J, Zhuang L. Effect of heating rate on mechanical property, microstructure and texture evolution of Al-Mg-Si-Cu alloy during solution treatment. Materials Science and Engineering: A. 2015;621:8-17.

8. Guo F, Zhang D, Fan X, Jiang L, Yu D, Pan F. Deformation behavior of AZ31 Mg alloys sheet during large strain hot rolling process: A study on microstructure and texture evolutions of an intermediate-rolled sheet. Journal of Alloys and Compounds. 2016;663:140-147.

9. Zhang LX, Chen WZ, Zhang WC, Wang W, Wang E. Microstructure and mechanical properties of thin ZK61 magnesium alloy sheets by extrusion and multi-pass rolling with lowered temperature. Journal of Materials Processing Technology. 2016;237:65-74.

10. Gatti JR, Bhattacharjee PP. Annealing textures of severely cold and warm-rolled Al-2.5 wt.\%Mg alloy. Journal of Alloys and Compounds. 2014;615:950-961.

11. Chen Y, Tian N, Zhao G, Liu C, Zuo L. Evolution of $\{001\}$ $<110>$ orientation and related lattice rotation of $\mathrm{Al}$ alloy 6111 during rolling. Transactions of Nonferrous Metals Society of China. 2007;17(3):523-530.

12. Lapovok R, Timokhina I, McKenzie PWJ, O’Donnell R. Processing and properties of ultrafine-grain aluminium alloy 6111 sheet. Journal of Materials Processing Technology. 2008;200(1-3):441-450.

13. Su L, Lu C, Gazder AA, Saleh AA, Deng G, Tieu K, et al. Shear texture gradient in AA6061 aluminum alloy processed by accumulative roll bonding with high roll roughness. Journal of Alloys and Compounds. 2014;594:12-22.

14. Barnwal VK, Raghavan R, Tewari A, Narasimhan K, Mishra SK. Effect of microstructure and texture on forming behaviour of AA-6061 aluminium alloy sheet. Materials Science and Engineering: A. 2017;679:56-65.

15. Yang X, Wang D, Wu Z, Yi J, Ni S, Du Y, et al. A coupled EBSD/TEM study of the microstructural evolution of multiaxial compressed pure $\mathrm{Al}$ and $\mathrm{Al}-\mathrm{Mg}$ alloy. Materials Science and Engineering: A. 2016;658:16-27.

16. Zhao Q, Liu Z, Huang T, Xia P, Li F. Enhanced fracture toughness in an annealed $\mathrm{Al}-\mathrm{Cu}-\mathrm{Mg}$ alloy by increasing Goss/Brass texture ratio. Materials Characterization. 2016;119:47-54.

17. Wang JS, Hsieh CC, Lin CM, Kuo CW, Wu W. Texture Evolution and Residual Stress Relaxation in a Cold-Rolled Al-Mg-Si-Cu Alloy Using Vibratory Stress Relief Technique. Metallurgical and Materials Transactions A. 2013;44(2):806-818.

18. Wang X, Guo M, Zhang Y, Xing H, Li Y, Luo J, et al. The dependence of microstructure, texture evolution and mechanical properties of $\mathrm{Al}-\mathrm{Mg}-\mathrm{Si}-\mathrm{Cu}$ alloy sheet on final cold rolling deformation. Journal of Alloys and Compounds. 2016;657:906916.

19. Quadir MZ, Al-Buhamad O, Bassman L, Ferry M. Development of a recovered/recrystallized multilayered microstructure in Al alloys by accumulative roll bonding. Acta Materialia. 2007;55(16):5438-5448.

20. Yang H. Key factors for warm rolled bond of 6111-aluminium strip. Transactions of Nonferrous Metals Society of China. 2006; 16:84-90.

21. Yang X, Ni S, Song M. Partial dislocation emission in a superfine grained Al-Mg alloy subject to multi-axial compression. Materials Science and Engineering: A. 2015;641:189-193.

22. Ruggles TJ, Fullwood DT, Kysar JW. Resolving geometrically necessary dislocation density onto individual dislocation types using EBSD-based continuum dislocation microscopy. International Journal of Plasticity. 2016;76:231-243.

23. Wallis D, Hansen LN, Britton TB, Wilkinson AJ. Geometrically necessary dislocation densities in olivine obtained using high-angular resolution electron backscatter diffraction. Ultramicroscopy. 2016;168:34-45. 